\title{
Comparative Studies on the Production and Assay of Interferon
}

\author{
By G. E. GIFFORD*, MARJORIE V. MUSSETT \\ AND E. HELLER \\ National Institute for Medical Research, London, N.W.7, England
}

(Received 3 September 1963)

\section{SUMMARY}

Interferon was produced in chick embryo cell cultures or in chick embryos by five viruses and in mouse embryo cell cultures or mouse lungs by two viruses. The slopes of the log dose response lines for the five chick interferons were compared by using vaccinia virus as the assay virus. Analysis of variance showed that they did not differ significantly. Partially purified interferon gave the same slope as the crude preparations. These findings allowed a comparison to be made of relative yields of interferon induced by different viruses in the same cell system. Viruses differed widely in their ability to induce interferon. Chikungunya virus induced about 70 times more interferon than did vaccinia or Newcastle disease virus and $2 \cdot 6$ times more interferon than Kumba virus. The slopes of the log dose response lines for two interferon preparations were compared by using Chikungunya virus as the assay virus. Analysis of variance showed that they were not significantly different. A comparison of the vaccinia and Chikungunya assays for interferon showed that the Chikungunya assay was approximately $\mathbf{2 \cdot 9}$ times more sensitive when the amount of interferon depressing the plaque count by $50 \%$ (PDD 50 doses) were compared. An analysis of variance showed that the difference in slope between the two assays was small but approaching significance. Mouse interferon, induced by two viruses, yielded parallel dose response lines. However, the slope of the curves for mouse interferon was significantly different from that for chick interferon. Because of this difference in slope, interferon production by the same virus in the two cell types could not be validly compared.

\section{INTRODUCTION}

Different batches of interferon induced in chick embryos by the same strain of influenza virus gave parallel dose-response curves (Lindenmann \& Gifford, 1963), allowing estimates to be made of the relative potencies of different interferon preparations. Comparative dose-response curves for interferon induced by different viruses under similar conditions have not been published. In the present study the dose response lines of five interferons induced by five viruses in chick cells and two interferons induced in mouse cells by two viruses were compared. The sensitivities of two different plaque assays for interferon were compared.

\section{METHODS}

Interferon production. Mouse interferon was prepared by the intranasal inoculation of mice with about $600 \mathrm{egg}$ infectious doses of the PR 8 strain of influenza $A$ virus

* Present address: Department of Microbiology, University of Florida College of Medicine, Gainesville, Florida, U.S.A. 
as described by Isaacs \& Hitcheock (1960). Lungs were removed 3 days later, triturated with Gey's balanced salt solution (BSS), centrifuged at about $1500 \mathrm{rev} . /$ min. for $30 \mathrm{~min}$. and the supernatant fluid containing the interferon collected. This interferon preparation was dialysed against $0.1 \mathrm{M}-\mathrm{HCl}+\mathrm{KCl}$ buffer $(\mathrm{pH} 2)$ overnight and then against Gey's BSS to bring to about $\mathrm{pH}$ 7·4. A second mouse interferon was produced by infecting mouse embryo cell cultures with Newcastle disease virus at an input multiplicity of about 0.05 plaque forming units (pfu)/cell and incubating at $37^{\circ}$ for $24 \mathrm{hr}$. Since dialysis overnight against $\mathrm{pH} 2$ buffer did not completely inactivate this virus the preparation was treated with perchloric acid, $0 \cdot 15 \mathrm{~N}$ at $5^{\circ}$, as described by Lampson, Tytell, Nemes \& Hilleman (1963), centrifuged, and then dialysed against BSS to remove the perchloric acid.

Chick interferon was also produced in two ways. Chick embryos (10-day) were inoculated with the Mel strain of Influenza A virus and incubated for $72 \mathrm{hr}$ at $35^{\circ}$. The allantoic fluid was collected, centrifuged, and dialysed against $\mathrm{pH} 2$ buffer overnight and then against BSS to restore to about $\mathrm{pH} 7 \cdot 4$. Chick interferon was also prepared in monolayer cultures of chick embryo cells. The same batch of cells and medium, at $35^{\circ}$ was used to produce interferon by four different viruses. The four viruses (Chikungunya, Kumba, vaccinia, Newcastle disease) were used at an input multiplicity of $0.06 \mathrm{pfu} /$ cell since this was near the optimal amount of virus for maximal production of interferon by Chikungunya virus in chick cells (Gifford, $1963 \mathrm{a}$ ). Cultures were incubated at $37^{\circ}$ for $24 \mathrm{hr}$ and the supernatant fluid removed, centrifuged to remove debris, and treated with perchloric acid as described for the mouse interferon induced with Newcastle disease virus. Fresh medium was placed in these bottles and they were incubated for a further $24 \mathrm{hr}$. The amount of interferon produced in the second $24 \mathrm{hr}$ incubation period amounted to less than $10 \%$ of the first 24 hr yield.

Cell cultures. Monolayer cultures of chick embryo cells were prepared as described by Porterfield (1960). Cells were suspended in growth medium and, for interferon assay with vaccinia virus, about $9 \times 10^{6}$ cells were dispensed in $3 \mathrm{ml}$. volumes into $1 \mathrm{oz}$. 'medical' screw-capped bottles having a rectangular side of $18 \mathrm{~cm}^{2}$. These cultures were incubated (bottles flat) at $37^{\circ}$ and used $42-48 \mathrm{hr}$ later when there were approximately $3 \times 10^{6}$ cells/bottle as a monolayer. For the Chikungunya assays, cells were dispensed into the same type of bottle but at twice the concentration. For interferon production, $64 \times 10^{6}$ cells were dispensed into $8 \mathrm{oz}$. bottles with a rectangular surface area of $72 \mathrm{~cm}^{2}$. Twenty-four hr later these cultures contained about $20 \times 10^{6}$ cells attached to the glass. Mouse fibroblast monolayers were prepared by trypsinizing 18- to 20-day eviscerated mouse embryos in a manner similar to the chick embryos. $60 \times 10^{6}$ cells were dispensed in $12 \mathrm{ml}$. medium into $8 \mathrm{oz}$. bottles and incubated for 2-6 days. These primary mouse fibroblasts were then re-trypsinized and dispensed into $1 \mathrm{oz}$. bottles with $3 \times 10^{6}$ cells/bottle in $3 \mathrm{ml}$. medium. They were used on the following day and contained about $3 \times 10^{6}$ cells as a monolayer.

Media. The same medium, with slight modifications, was used for both the mouse and chick cells. Growth medium for the establishment of chick monolayers consisted of BSS with 0.0025 M-2-amino-2-(hydroxymethyl)-1,3-propanediol (tris), $5 \%$ $(\mathrm{v} / \mathrm{v})$ calf serum, $0.25 \%(\mathrm{w} / \mathrm{v})$ lactalbumin hydrolysate, and $0.1 \%(\mathrm{w} / \mathrm{v})$ proteose peptone. The same medium was used for the establishment of mouse cells except that the serum was increased to $10 \%$ and $0 \cdot 11 \%(\mathrm{w} / \mathrm{v})$ sodium bicarbonate replaced 
the tris buffer. Maintenance medium, used for virus and interferon assays with vaccinia virus in chick and mouse cultures consisted of BSS with $0 \cdot 11 \%$ sodium bicarbonate, $0 \cdot 25 \%$ lactalbumin hydrolysate, $0.1 \%$ yeast extract, and $0.1 \%$ proteose peptone. For Chikungunya assays of virus and interferon, the overlay consisted of $0.75 \%$ agar (Noble), $5 \%$ calf serum, $0.0025 \mathrm{M}$-tris, $0.25 \%$ lactalbumin hydrolysate, and $0.1 \%$ proteose peptone in BSS.

Virus and interferon assays. Vaccinia virus and interferon were titrated according to the method described by Lindemann \& Gifford (1963) with slight modification. Assay cultures were incubated at $35^{\circ}$ instead of $37^{\circ}$ since the plating efficiency of vaccinia virus was thus increased by about $15 \%$. Interferon was also assayed with Chikungunya virus by the method described by Ruiz-Gomez \& Isaacs (1963). In all interferon assays, four cultures were used for each interferon dilution.

Protein determinations. Protein was estimated by the Folin phenol method (Lowry, Rosebrough, Farr \& Randall, 1951).

Partial purification of interferon. Interferon produced in chick cells with Chikungunya virus was treated with perchloric acid, centrifuged, and precipitated twice with zinc acetate (Lampson et al. 1963). About $81 \%$ of the protein was removed.

Viruses. Vaccinia, Chikungunya, Newcastle disease, Kumba (Semliki Forest) and Influenza A (PR 8 and Mel) viruses were used. Chikungunya and Kumba viruses were grown in the brains of newborn mice. Influenza and Newcastle disease viruses were grown in the allantoic cavity of 10-day embryonated chicken eggs. Vaccinia virus was grown on the chorioallantois of 10- to 12-day chick embryos. All viruses were stored in glass capillaries at $-60^{\circ}$.

\section{RESULTS}

Eleven assays were made and dose response graphs constructed of percent plaque inhibition against $\log . \mu \mathrm{l}$. interferon used (assays 1-11, Table 1). Tests for linearity showed that none of the sets of points deviated significantly from a straight line when plaque inhibition between 10 and $90 \%$ was considered.

Comparison of the dose response of two interferon preparations assayed with Chikungunya virus. Two interferon preparations induced with Chikungunya virus in chick cells were assayed with Chikungunya virus (Fig. 1; assays 8 and 9, Table 1 ). The difference between the slopes for these two assays was not significant at the $20 \%$ level when examined as the 'departure from parallelism' term in an analysis of variance (i.e. the probability that the difference in slope might be obtained by chance is greater than 1 in 5). This was also shown by the variance of the slope in Table 1. These results indicated that Chikungunya virus would give parallel dose response lines with different preparations of interferon, as previously shown with vaccinia virus (Lindenmann \& Gifford, 1963).

Comparison of the Chikungunya and vaccinia assays for interferon. Chikungunya and vaccinia assays were performed on the same batch of cells at the same time using the same interferon preparation. There were marked differences in the assay procedures. The Chikungunya assay was done with overnight pre-incubation of cells with interferon, virus was then allowed to adsorb for $1 \mathrm{hr}$ and an agar overlay containing serum added. In the vaccinia assay, virus and interferon dilutions were added at the same time, the cell concentration was different and no agar or serum 


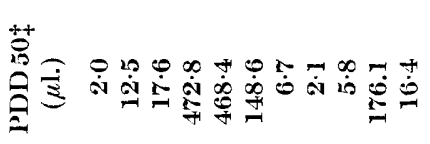

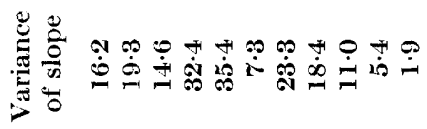

离

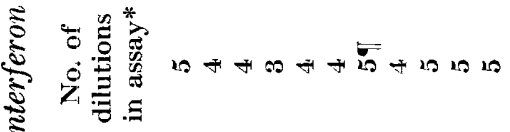

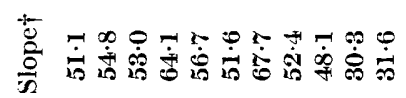

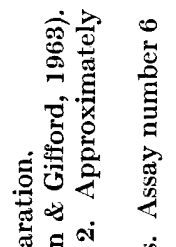

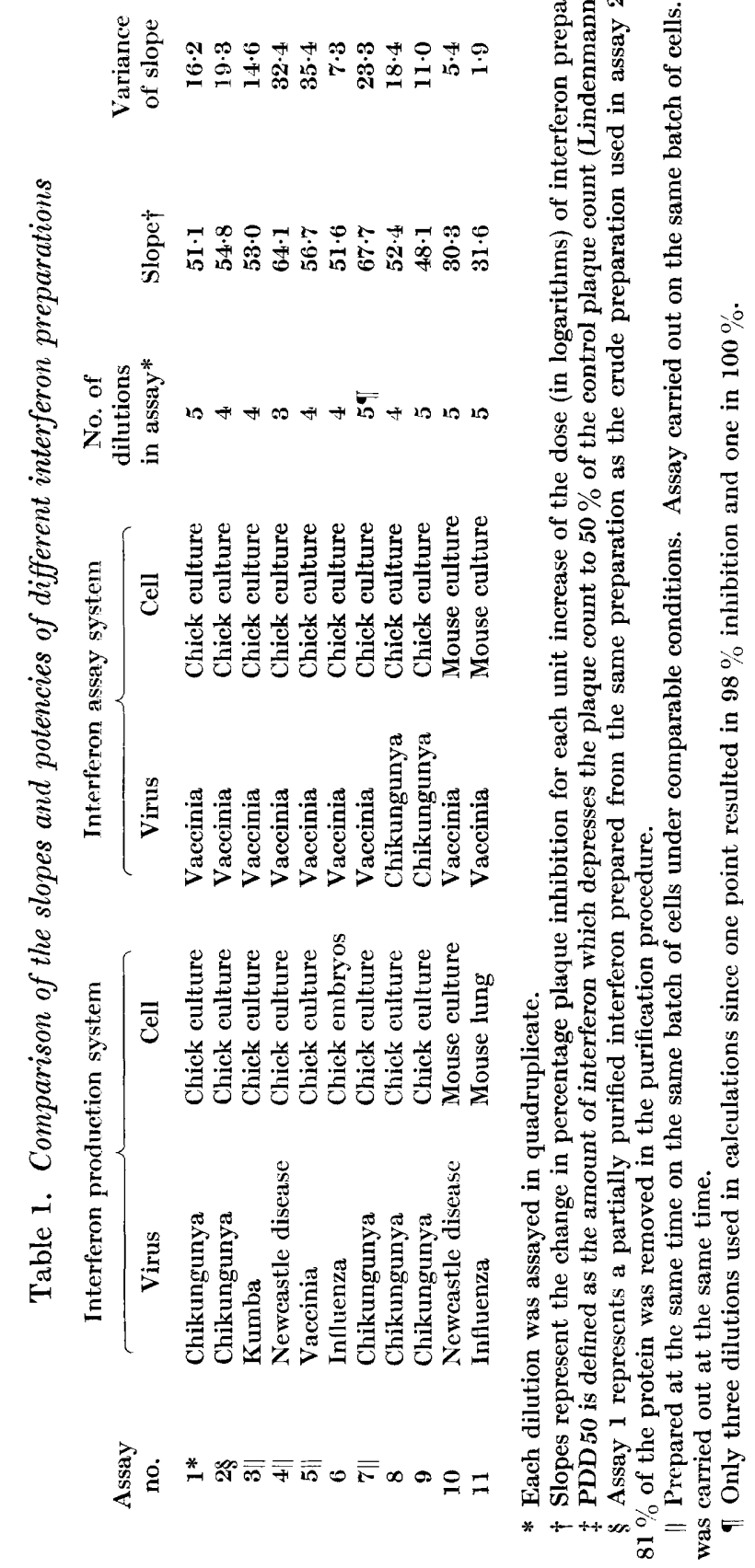


was used (Fig. 2; assays 7 and 8, Table 1). Analysis of variance showed the difference in slope between these two log dose response lines to be just significant at the $5 \%$ level. As this is generally considered to be on the borderline of significance the result is difficult to interpret, but it may be noted that the slope for the vaccinia assay is the largest of all the slopes in the vaccinia series (assays 1-7). The slopes represent the change in percentage plaque inhibition for each unit increase of the dose (expressed in logarithms) of interferon preparation. The weighted mean slope for all vaccinia assays was $\mathbf{5 5 \cdot 1}$ and the corresponding weighted mean slope for Chikungunya assays was $49 \cdot 7$, a difference which is approaching significance $(t=1.75 ; 0.10>p>0.05)$. If the lines for the Chikungunya and vaccinia assays could be considered parallel and therefore a valid comparison made, then the

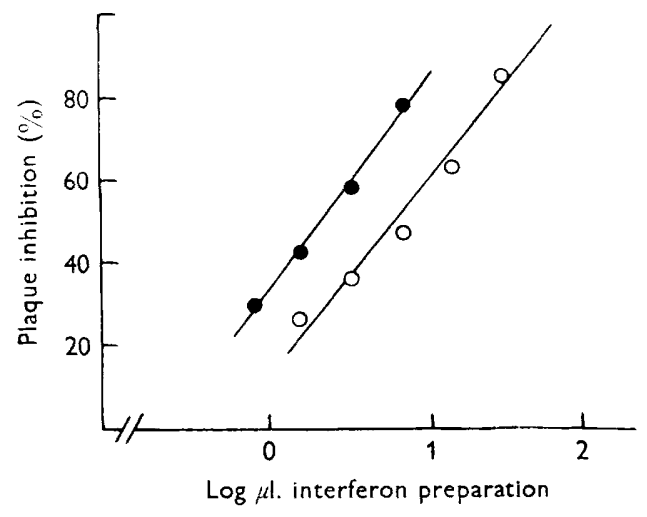

Fig. 1

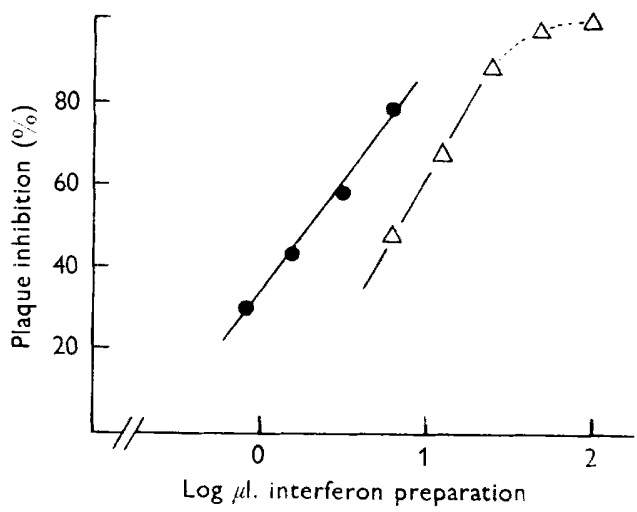

Fig. 2

Fig. 1. Comparison of the dose response of two interferon preparations assayed with Chikungunya virus. $O$ and $O$ represent two interferons induced with Chikungunya virus in chick cell cultures.

Fig. 2. Comparison of the Chikungunya and vaccinia assays for interferon. Both assays were done with the same interferon preparation and on the same batch of cells. $\times=$ Chikungunya assay; $\triangle=$ vaccinia assay.

Chikungunya assay would be $\mathbf{2} \cdot 9$ times more sensitive than the vaccinia assay when the $\log$ PDD 50 doses were compared. However, the vaccinia virus assay was used in all subsequent studies because of its simplicity and because induction of interferon by the assay virus was less of a complication.

Comparison of crude and partially purified interferon. Interferon induced in chick cell cultures with Chikungunya virus was partially purified. The dose responses of the crude and purified preparations were assayed using vaccinia virus as the assay virus (Fig. 3; assays 1 and 2 Table 1). The difference between the slopes for these two assays was not significant and the partially purified and concentrated material showed about 6 times the activity of the crude preparation.

Comparison of the yield of interferon by four viruses in chick cells. Interferon production was induced in chick cells with four different viruses (Kumba, Newcastle disease, vaccinia, Chikungunya) using the same conditions of culture and the relative potencies compared. Another interferon produced in chick embryos infected with influenza virus was assayed at the same time (Fig. 4; assays 3-7 Table 1). The data 
for the five assays were considered in a single analysis of variance which showed that the slopes calculated for the five lines might all be regarded as estimates of the same slope, for the variance due to non-parallelism was only 1.7 times the residual error of the experiment, a value which might be expected to occur by chance between 1 in 5 and 1 in 10 times. About 70 times more interferon was produced by Chikungunya virus than by Newcastle disease or vaccinia viruses and $\mathbf{2 \cdot} \mathbf{6}$ times more than by Kumba virus.

Comparison of the dose response of mouse interferon. Two mouse interferons, produced by different viruses, were assayed in mouse cells with vaccinia virus (Fig. 5; assays 10-11 Table 1). Analysis of variance gave a probability of greater than $20 \%$ for the departure from parallelism term. The weighted mean slope for these two assays $(31 \cdot 24)$ was significantly less than the slopes for the chick assays at the $\mathbf{0 . 1} \%$ level. A valid comparison of the amount of interferon produced by a given virus in these different cell types could not be made.

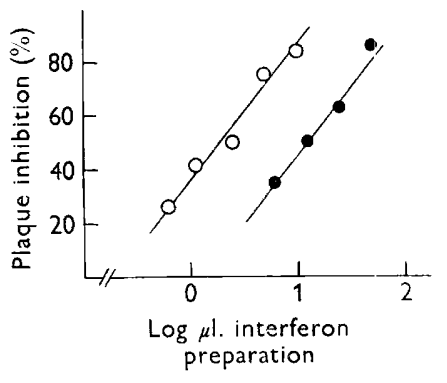

Fig. 3

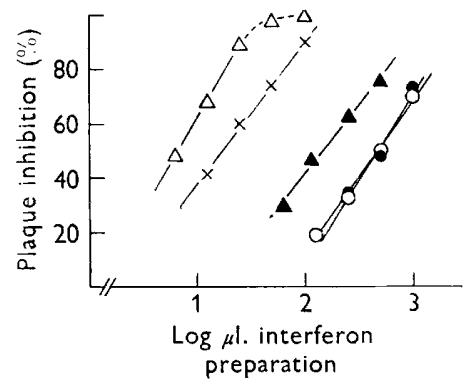

Fig. 4

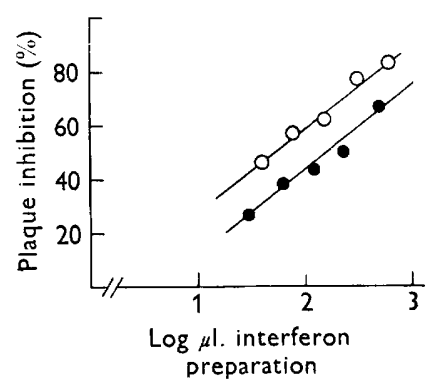

Fig. 5

Fig. 3. Comparison of crude and partially purified interferon. $O=$ partially purified; - crude preparation from which the partially purified was derived.

Fig. 4. Comparison of the yield of interferon by different viruses in chick cells. Interferons induced by the different viruses are represented by: $\Delta=$ Chikungunya; $x=$ Kumba, $\boldsymbol{\Delta}=$ influenza; $\boldsymbol{O}=$ vaccinia and $O=$ Newcastle disease.

Fig. 5. Comparison of the dose response of two mouse interferon preparations. $O=$ interferon induced in mouse lungs with influenza virus; 0 = interferon induced in mouse cell cultures with Newcastle disease virus.

\section{DISCUSSION}

Plaque inhibition assays of interferon have been used by many workers. The measure of interferon activity employed has usually been the dose depressing the plaque count to $50 \%$ of the controls for which the abbreviation PPD $50(50 \%$ plaque depressing dose) has been suggested (Lindenmann \& Gifford, 1963). Relative potencies can only be estimated for preparations yielding parallel dose-response curves when the response is plotted against the logarithm of the dose. Factors which alter the shape of the dose-response curve for interferon are unknown. It was thought that variations might be expected with interferon preparations induced with different viruses, since it was possible that in some preparations of interferon there might be materials which exert an antagonistic or potentiating effect or affect stability of interferon. However, it was interesting that the dose-response curves obtained with interferon induced with several different viruses, demonstrated 
parallel lines. These findings give further evidence that the same interferon is induced by different viruses. The reasons for the quantitative differences in interferon production by different viruses remains unknown. The same slope was consistently found for many interferon preparations produced over several months and also with partially purified preparations. Variations were encountered in potency estimations when the same interferon preparation was used on various batches of cells as previously reported (Lindenmann \& Gifford, 1963). Changes in pH, temperature, and volume of overlay medium did not appear to markedly alter the shape of the dose response curves (Gifford, unpublished observations).

Although the significance of the dose-response slopes with respect to the mechanism of action of interferon is unknown, it is of interest that the slopes for mouse and chick interferon were markedly different. It has been shown (Gifford, 1963b) that the slopes of chick and mouse interferons, when assayed on both homologous and heterologous cell systems, were characteristic of the cell type in which interferon had been produced and not the cell type in which it was assayed.

We wish to acknowledge the excellent technical assistance of Mr C. Gilchrist and Mrs Barbara Knight. We also wish to thank Miss Hilary Prince for performing the protein determinations. This investigation was supported in part by a Public Health Service Fellowship (ESP-17932) from the National Institute of Allergy and Infectious Diseases, Public Health Service, U.S.A. (to G.E.G.) and a Fellowship from the Leukemia Society, Inc., New York, U.S.A. (to E.H.).

\section{REFERENCES}

Gifford, G. E. $(1963 a)$. Variation of interferon yield with multiplicity of infection. Nature, Lond. $200,91$.

Gifford, G. E. $(1963 b)$. Studies on the specificity of interferon. J. gen. Microbiol. (in the Press).

IsaAcs, A. \& Hiтchсоск, G. (1960). Role of interferon in recovery from virus infections. Lancet, ii, 69.

Lampson, G. P., Tytell, A. A., Nemes, M. M. \& Hilleman, M. R. (1963). Purification and characterization of chick embryo interferon. Proc. Soc. exp. Biol., N.Y. 112, 468.

Lindenmann, J. \& Gifford, G. E. (1963). Studies on vaccinia virus plaque formation and its inhibition by interferon. III. A simplified plaque inhibition assay of interferon. Virology, 19, 302.

Lowry, O. H., Rosebrough, N. J., Farr, A. L. \& Randall, R. J. (1951). Protein measurement with the folin phenol reagent. J. biol. Chem. 193, 265.

Porterfield, J. S. (1960). A simple plaque inhibition test for the study of arthropodborne viruses. Bull. Wld Hlth Org. 22, 373.

Ruiz-Gomez, J. \& IsAacs, A. (1963). Optimal temperature for growth and sensitivity to interferon among different viruses. Virology, 19, 1. 